\title{
Estudo da Influência do Boro no Aço 10B45 (Fio-máquina e Arame Trefilado), analisando propriedades mecânicas e microestruturas
}

\section{Study of the Influence of Boron on Steel 10B45 (wire rods and drawn Wire) analyzing mechanical properties and microstructures}

\author{
1 Viviane de Melo Borges borges.vm@gmail.com \\ 2 Jefferson Fabrício Cardoso Lins
}

\footnotetext{
Mestranda em engenharia metalúrgica - Universidade Federal Fluminense, campus Volta Redonda.

2 Docente do programa de pós-graduação em engenharia metalúrgica, da Universidade Federal Fluminense, campus Volta Redonda.
}

\section{Resumo}

O presente trabalho avaliou as influências da adição de diversos teores de boro nas características mecânicas e microestruturais do fio-máquina e arame trefilado no aço 10B45. Foi verificado que a adição de boro reduz a resistência do material, atuando sobre os mecanismos de envelhecimento, pois associa-se ao nitrogênio formando o nitreto de boro (BN) no contorno de grão. Assim, quanto maior a adição de boro, menor resistência à trefilação, o que pôde ser comprovado pelo ensaio de torção nos arames. Ainda foi possível avaliar o modo de fratura relacionado com a quantidade de boro adicionada. Nesse ponto, não foi possível atribuir maior ductilidade à amostra com maior teor de boro.

\section{Palavras-chave}

Boro. Nitreto de boro. Fio-máquina. Arames.

\begin{abstract}
This study evaluated the influences of adding various levels of boron in the mechanical and microstructural characteristics of wire rod and wire drawn in steel 10B45. It was verified that the addition of boron reduces the resistance of the material acting on the aging mechanisms because it associates with the nitrogen forming the boron nitride (BN) in the grain boundary. Thus, the higher the boron addition the lower tensile strength, which could be proved by the torsion test in the wires. It was still possible to evaluate the mode of fracture related to the amount of boron added. At this point it was not possible to assign higher ductility to the sample with higher boron content.
\end{abstract}

\section{Keywords}

Boron. Boron nitride. Wire rods. Drawn Wire.

\section{Como você deve citar?}

BORGES, Viviane de Melo; LINS, Jefferson Fabrício Cardoso. Estudo da Influência do Boro no Aço $10 B 45$ (Fio-máquina e Arame Trefilado), analisando propriedades mecânicas e microestruturas. Cadernos UniFOA, Volta Redonda, n. 36, p. 5-14, abr. 2018. 
Estudo da Influência do Boro no Aço 10B45 (Fio-máquina e Arame Trefilado),

analisando propriedades mecânicas e microestruturas

\section{INTRODUÇÃO}

Os aços carbono e microligados estão sempre evoluindo, a fim de atender um mercado que demanda menores custos e melhores propriedades mecânicas. Vários podem ser os elementos adicionados, no entanto, o boro se destaca, devido ao seu menor custo em relação aos demais. Pequenas dosagens são suficientes para garantir ao material boa temperabilidade, baixa dureza após laminação, alterações na ductilidade e redução dos efeitos do envelhecimento dinâmico, pelo efeito negativo do nitrogênio (MAITREPIERRE et al., 1979).

O mecanismo de envelhecimento clássico se deve à presença de solutos intersticiais, carbono e/ou nitrogênio, restringindo o movimento das discordâncias. Entretanto, devido à maior solubilidade do nitrogênio, este é o principal responsável pelo envelhecimento, apesar do carbono também poder contribuir para esse fenômeno em altas temperaturas. Dessa forma, é reconhecido que o soluto nitrogênio é prejudicial às propriedades de conformação a frio do aço (GONZALEZ et al., 2003). Reduzir o teor de nitrogênio livre é uma forma efetiva de fazer com que as discordâncias possam se mover mais facilmente, reduzindo o efeito do envelhecimento (REIS, 2009).

Para estabilizar ou eliminar a consequência do nitrogênio. São adicionados formadores de nitretos, dentre eles. 0 boro, titânio, alumínio, vanádio e nióbio. Há inúmeras vantagens de se utilizar o boro na formação de nitretos, dentre elas, o baixo custo da liga de ferro-boro e sua eficiência estequiométrica com o nitrogênio (COE et al., 2006). Os nitretos de boro formados não são prejudiciais ao arame, devido ao seu pequeno tamanho (COE et al., 2006).

Além da formação de nitretos e da redução dos efeitos do envelhecimento, a adição de boro tem efeito positivo na trefilação. Como o boro em solução sólida é um importante elemento inibidor da formação de ferrita, evita efetivamente trincas longitudinais na superfície do arame (NAGAO, 1954; MAKKI et al., 2001).

\section{MATERIAL E MÉTODOS}

O aço utilizado para este estudo é o 10B45 com níveis de nitrogênio de, aproximadamente, 90 ppm. Esse nível de nitrogênio confirma que o efeito do envelhecimento nesse aço é relevante. Por isso, neste trabalho, o estudo da adição de boro será voltado para avaliar esse comportamento específico.

\subsection{Material}

Os lotes comerciais utilizados para este trabalho foram produzidos na Unidade Resende da Votorantim Siderurgia. As composições químicas estão apresentadas na Tabela 1.

Tabela 1 - Composição química das amostras (\% em peso)

\begin{tabular}{lllllll}
\hline Lotes & Carbono & Fósforo & Enxofre & Manganês & Boro & Nitrogênio \\
\hline Lote 1 & 0,44 & 0,03 & 0,01 & 0,69 & 0,0000 & 0,0103 \\
Lote 2 & 0,45 & 0,03 & 0,01 & 0,68 & 0,0032 & 0,0090 \\
Lote 3 & 0,45 & 0,02 & 0,02 & 0,60 & 0,0047 & 0,0090 \\
Lote 4 & 0,46 & 0,03 & 0,01 & 0,63 & 0,0060 & 0,0089 \\
\hline
\end{tabular}

Fonte: Certificado de Qualidade Votorantim Siderurgia 


\subsection{Métodos}

\subsubsection{Produção}

Os lotes foram produzidos em aciaria elétrica, passando pelos processos de fusão e refino (forno elétrico), ajuste químico e térmico (forno-panela) e solidificação (lingotamento contínuo).

Em seguida, os tarugos foram laminados a quente, gerando um dos produtos da análise, 0 fio-máquina (FM) com diâmetro de $5,5 \mathrm{~mm}$. A velocidade do laminador foi de $105 \mathrm{~m} / \mathrm{s}$ e o tratamento térmico foi realizado com ar forçado. O FM foi, então, trefilado numa máquina de fieira de 8 passes com velocidade de $20 \mathrm{~m} / \mathrm{s}$. A redução total foi de $77 \%$, originando o arame ovalado de diâmetro de 2,65m.

\subsubsection{Processamento das amostras}

\section{a. Composição Química}

A composição química dos lotes foi analisada durante o processo do forno-panela, utilizando espectrômetro óptico (ARL 3460). A fim de resumir a composição química em uma única variável, foi calculado, para cada lote, o carbono equivalente (CEQ) correspondente. A fórmula utilizada foi conforme norma ABNT NBR 8965:1985.

$$
C E Q=C+\frac{M n}{6}+\frac{(C r+V+M o)}{5}+\frac{(C u+N i)}{15} \quad \text { Equação } 1
$$

\section{b. Ensaios de Tração e Torção}

Os ensaios de tração foram realizados conforme norma ABNT NBR ISO 6892-1:2013, nas amostras de fio-máquina e arames. A fim de verificar a ductilidade dos arames, foi realizado o ensaio de torção simples por meio da norma ABNT NBR 6003:1984. O ensaio consistiu em torcer as amostras em torno do próprio eixo e no mesmo sentido até sua ruptura. Foi considerado apenas o número completo de voltas para cada amostra. Para a aplicação pretendida, existe especificação empiricamente determinada de 25 voltas, no mínimo.

\section{c. Caracterização Metalográfica}

Para a caracterização metalográfica, foram retiradas amostras das seções transversais do fio-máquina e longitudinal para o arame trefilado. A preparação das amostras abrangeu as etapas de corte, embutimento, lixamento, polimento e ataque químico com o reagente nital $2 \%$.

As análises metalográficas foram realizadas por meio do microscópio ótico (Olympus BX51M) e um analisador de imagens (Analysis Image).

Para análise do tamanho de grão austenítico, foi utilizada a norma ABNT NBR 7555:1990. Amostras do fio-máquina foram aquecidas durante $3 \mathrm{~h}$ na temperatura de $950^{\circ} \mathrm{C}$. As condições de temperatura e tempo foram definidas a partir da temperatura de austenitização desse aço e também simulando as condições operacionais do forno de reaquecimento do laminador da Votorantim Siderurgia. 


\section{d. Análise Fractográfica}

Para a análise fractográfica, as imagens foram obtidas em microscópio eletrônico de varredura (LE 1450 VP modelo 7366). O equipamento foi operado no modo de elétrons retro espalhados com aceleração do feixe eletrônico de $20 \mathrm{kV}$. A distância de trabalho adotada foi da ordem de $14 \mathrm{~mm}$ e as imagens capturadas foram ampliadas em 2000 vezes.

O software livre Image $\mathrm{J}$ foi utilizado para quantificar o percentual presente das fases na microestrutura, obter o tamanho de grão médio e a quantidade de micro cavidades (dimples) presentes. Para cada análise, foram utilizadas 10 imagens.

\section{RESULTADOS}

\subsection{Fio-máquina}

A Tabela 2 apresenta as propriedades mecânicas do fio-máquina com suas respectivas variações. Foram introduzidos os valores de carbono equivalente (Ceq), para facilitar a análise comparativa.

Tabela 2 - Resultados de carbono equivalente e propriedades mecânicas

\begin{tabular}{lllll}
\hline Lotes & $\begin{array}{l}\text { Carbono equivalente } \\
\text { CEQ }(\%)\end{array}$ & $\begin{array}{l}\text { Limite de escoamento } \\
\text { LE }\left(\mathrm{kgf} / \mathrm{mm}^{2}\right)\end{array}$ & $\begin{array}{l}\text { Limite de resistência } \\
\text { LR }\left(\mathrm{kgf} / \mathrm{mm}^{2}\right)\end{array}$ & $\begin{array}{l}\text { Alongamento } \\
\operatorname{AL}(\%)\end{array}$ \\
\hline Lote 1 & 0,530 & 51,05 & 79,63 & 17,95 \\
Lote 2 & 0,599 & 53,68 & 82,77 & 16,87 \\
Lote 3 & 0,587 & 52,25 & 80,12 & 17,85 \\
Lote 4 & 0,603 & 49,27 & 77,85 & 18,40 \\
\hline
\end{tabular}

Fonte: Do autor, 2018.

Nota-se a redução do LE e LR com o aumento do teor do boro entre os Lotes 2, 3 e 4, confirmando a atuação desse elemento na redução do efeito do envelhecimento.

Ressalva-se que o Lote 1 ( 0 ppm B) obteve resultados inferiores aos Lotes 2 e 3 . Isso pode ser explicado, pois o Lote 1 obteve um valor de CEQ inferior aos demais. Nesse caso, as propriedades desse lote foram afetadas pela variação da composição química. 0 valor da propriedade mecânica do Lote 1 (0 ppm B) foi superior apenas ao Lote 4 (60 ppm B), o que sugere inversão dos efeitos mencionados.

A Figura 1 ilustra as curvas compiladas de tensão versus deformação. Utilizou-se as curvas com resultados mais próximos dos valores médios apresentados na Tabela 2. 
Figura 1 - Curvas compiladas tensão versus deformação para o FM 5,5mm no aço 10B45. Em destaque, a região de serrilhamento do gráfico.

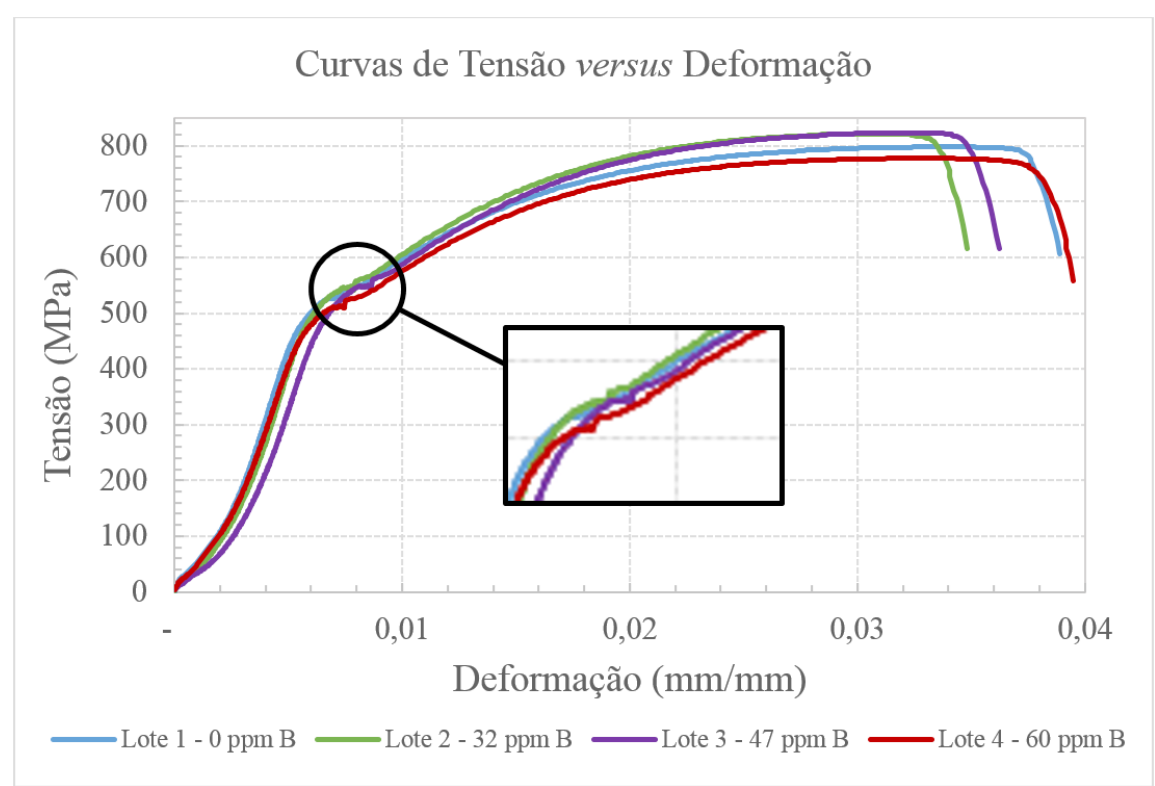

Fonte: Do autor, 2018.

A Figura 1 destaca as diferenças entre LE e LR, já mencionadas. Nota-se que na área de encruamento é possível identificar uma região de serrilhamento, também conhecido como efeito de Portevin-LeChatelier. Em aços comerciais, esse fenômeno acontece em função da interação, durante a deformação, das discordâncias com os átomos de nitrogênio. Ou seja, como se houvesse "travamentos" para deslocamento das discordâncias, pelo nitrogênio livre na matriz. A identificação da região de serrilhamento denota o efeito causado pelo envelhecimento nos aços (TAHERI et al., 1995).

Em relação às microestruturas do fio-máquina, os efeitos esperados relacionados à adição de boro são a variação do percentual das fases presentes e do tamanho do grão.

Segundo o estudo de Shen e Priestner (1990), a adição de boro modifica sensivelmente o diagrama Fe-C. A presença do boro desloca o ponto eutetoide para a esquerda, reduzindo a formação de ferrita pró-eutetoide por reduzir a energia livre nos contornos de grãos austeníticos. Essa condição foi comprovada a partir da quantificação das fases entre os Lotes 1 (0 ppm de B) e 4 (60 ppm de B), destacada na Figura 2. No lote sem boro, há, aproximadamente, $26 \%$ de fase ferrítica, enquanto que, no lote com 60 ppm de boro, há uma redução para 15\% dessa mesma fase. 
Figura 2 - Micrografias de FM na secção transversal de laminação, relacionadas ao seu respectivo histograma de quantificação de fase ferrítica, sendo: a) Lote 1 (0 ppm B) e b) Lote 4 (60 ppm B).

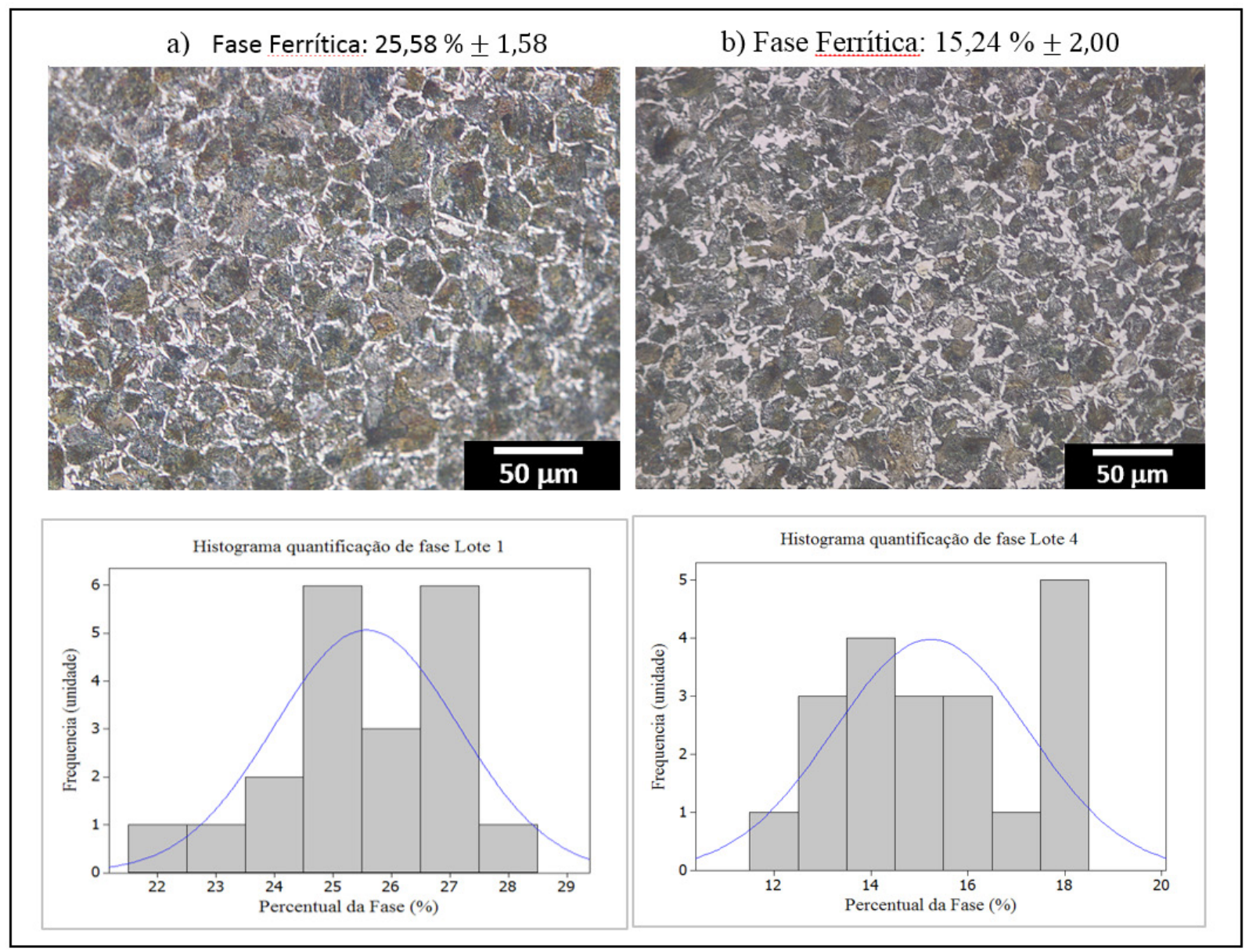

Fonte: Do autor, 2018.

Além do impacto no diagrama ferro-carbono, a adição de boro também pode impactar no tamanho do grão austenítico. De acordo com (REIS, 2009), a precipitação de BN no contorno de grão austenítico impede o mesmo de crescer durante o processo de aquecimento. Na Figura 3, é possível confirmar que os grãos austeníticos do Lote 1 (a) são maiores em relação ao Lote 4 (b). Para determinar a diferença, foi realizado a análise do tamanho de grão austenítico. A adição de 60 ppm de boro implicou em uma redução do tamanho de grão austenítico da ordem de $37 \%$. 
Figura 3 - Micrografias de fio-máquina após tratamento para revelação do tamanho do grão austenítico. Onde, a) Lote 1 (0 ppm B) e b) Lote 4 (60 ppm B).

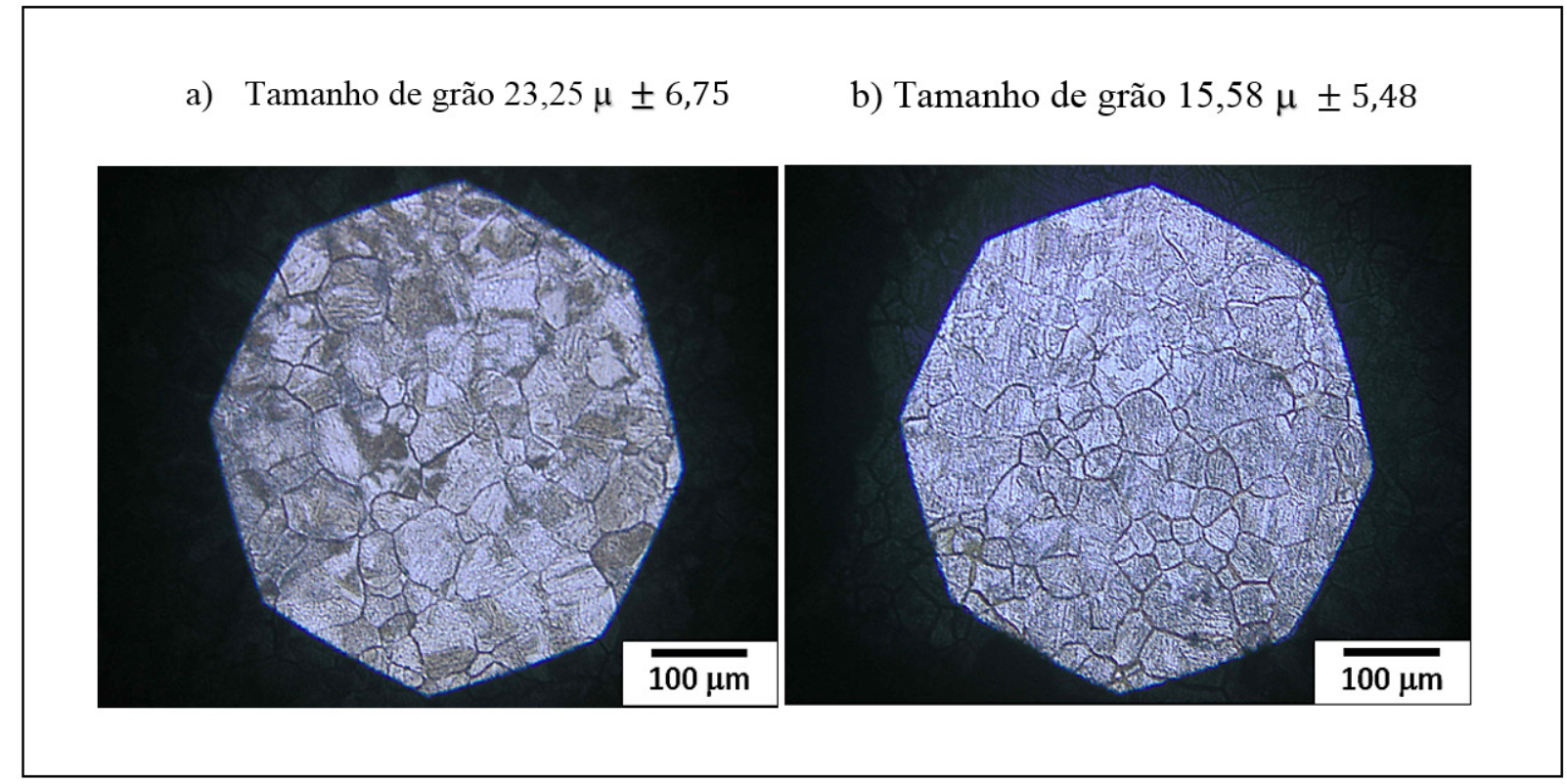

Fonte: Do autor, 2018.

A redução do tamanho de grão poderia sugerir valores de limite de resistência maiores. Esse ponto não foi confirmado neste trabalho, pois os efeitos da adição de boro e a redução de nitrogênio livre na matriz tiveram maior influência que o tamanho de grão. Pode-se afirmar que para esse material os efeitos do envelhecimento têm maior influência nas propriedades mecânicas.

Com o auxílio do microscópio eletrônico de varredura, foi realizada a análise de fratura em amostras de fio-máquina após o ensaio de tração dos lotes 1 e 4 . 0 objetivo foi identificar uma possível alteração do modo de fratura com a adição de boro.

A Figura 4 apresenta a formação e coalescimento de micro cavidades (dimples) equiaxiais de tamanhos variados. Os pontos destacados na figura são as regiões onde as imagens foram capturadas para a análise.

Através das análises das imagens, não foi possível identificar variação na ductilidade dos materiais em função do teor de boro. É possível apenas afirmar que ambas as fraturas são dúcteis. 
Figura 4 - Imagem (MEV) no modo de elétrons retroespalhados $20 \mathrm{kV}$ e WD de $14 \mathrm{~mm}$ da fratura do fio-máquina após o ensaio de tração, sendo: a) Lote 1 (0 ppm B) e b) Lote 4 (60 ppm B)

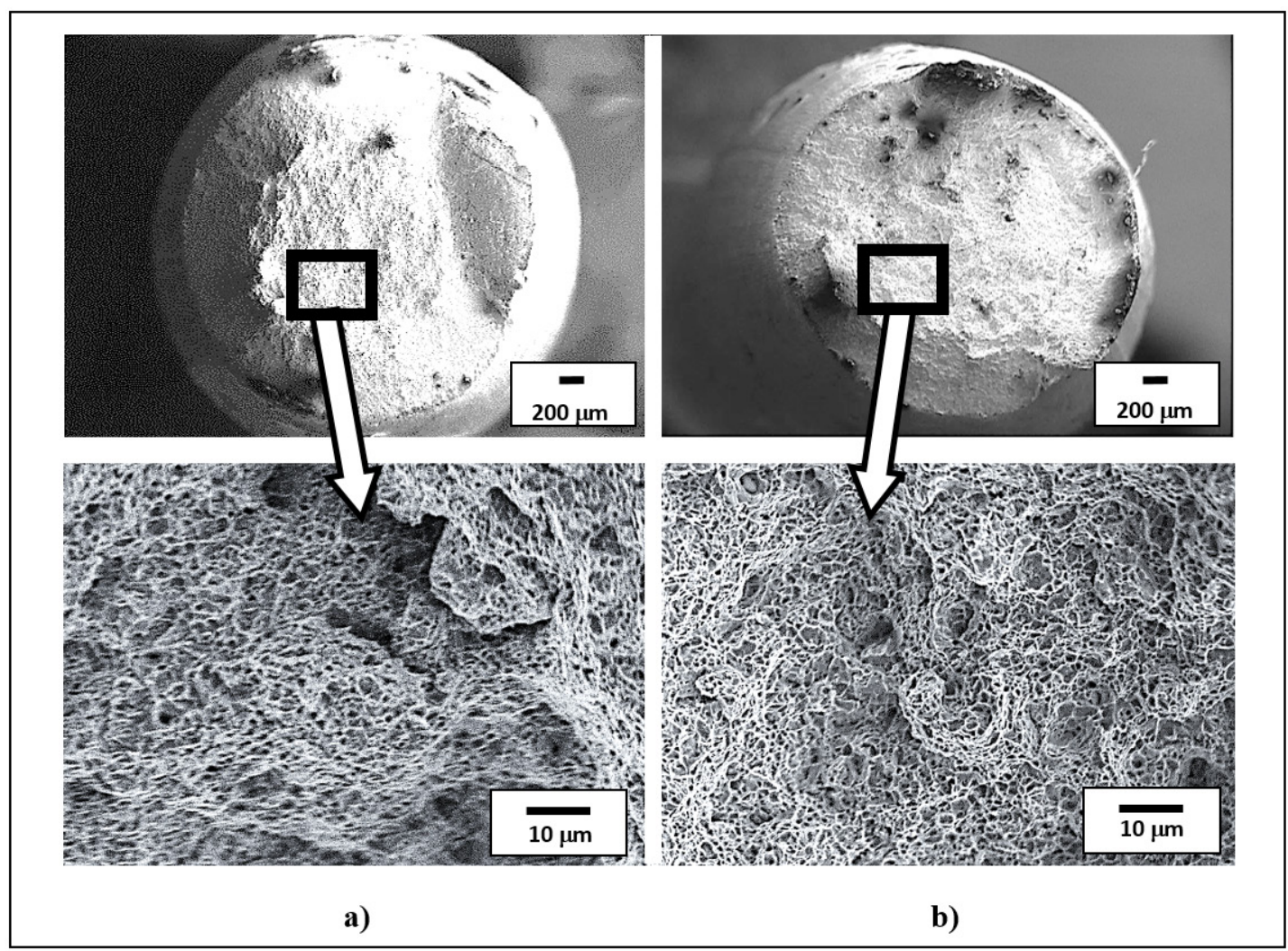

Fonte: Do autor, 2018.

\subsection{Arame Trefilado}

Os limites de resistência para o arame trefilado foram: $143 \mathrm{kgf} / \mathrm{mm}^{2}$, para o lote $1 ; 141 \mathrm{kgf} / \mathrm{mm}^{2}$, para o lote 2; $133 \mathrm{kgf} / \mathrm{mm}^{2}$, para o lote 3 ; e $132 \mathrm{kgf} / \mathrm{mm}^{2}$, para o lote 4 . Verifica-se que a influência do CEQ no fio-máquina para o Lote 1 não foi evidenciado no arame. Esse resultado sugere que os efeitos relacionados à alteração da morfologia dos grãos (encruamento) são maiores que os impactos relacionados à composição química. Assim, para essa propriedade mecânica, há um comportamento descendente entre o Lote 1 ao 4, obtendo-se redução de $11 \mathrm{kgf} / \mathrm{mm}^{2}$ com a adição de 60 ppm de boro. Dessa maneira, quanto maior o percentual de boro adicionado, menor a quantidade de nitrogênio livre na matriz e, portanto, menor resistência ao movimento das discordâncias.

A redução no limite de resistência é confirmada, de acordo com os estudos de (GONZALES et al., 2003) pelo motivo do nitreto de boro, o qual é formado no contorno de grão, atuar como lubrificante durante a trefilação.

A Figura 5 ilustra os resultados dos testes de torção aplicados a quatro amostras de arame, de cada lote. De acordo com a aplicação desse produto (cercas em ramo agropecuário), o número mínimo de voltas exigido pelo mercado é de 25 voltas sem que haja nenhuma ruptura no arame. Os arames do Lote 1 (sem adição de boro) quebraram sem atingir o número mínimo de voltas. Já os Lotes 2, 3 e 4 (com adição de boro), tiverem performances similares e acima do limite mínimo estipulado.

A adição de boro elevou a ductilidade do material. Sem a presença de boro, o nitrogênio atuou com o elemento intersticial e evitou o movimento livre das discordâncias, o que resultou na quebra das amostras. 
Era esperado maior ductilidade para o Lote 4, seguidos dos lotes 3,2 e 1 . No entanto, o comportamento equivalente entre os Lotes 2, 3 e 4 sugere que na menor adição de boro efetuada - $32 \mathrm{ppm}$, o nitrogênio disponível da matriz já é segregado na forma de nitreto de boro. Assim, as maiores quantidades boro nos demais lotes não resultaram em maior ductilidade.

Figura 5 - Resultados dos testes de torção nos arames trefilados, onde Lote 1 (0 ppm B), Lote 2 (32 ppm B), Lote 3 (47 ppm B), Lote 4 (60 ppm B).

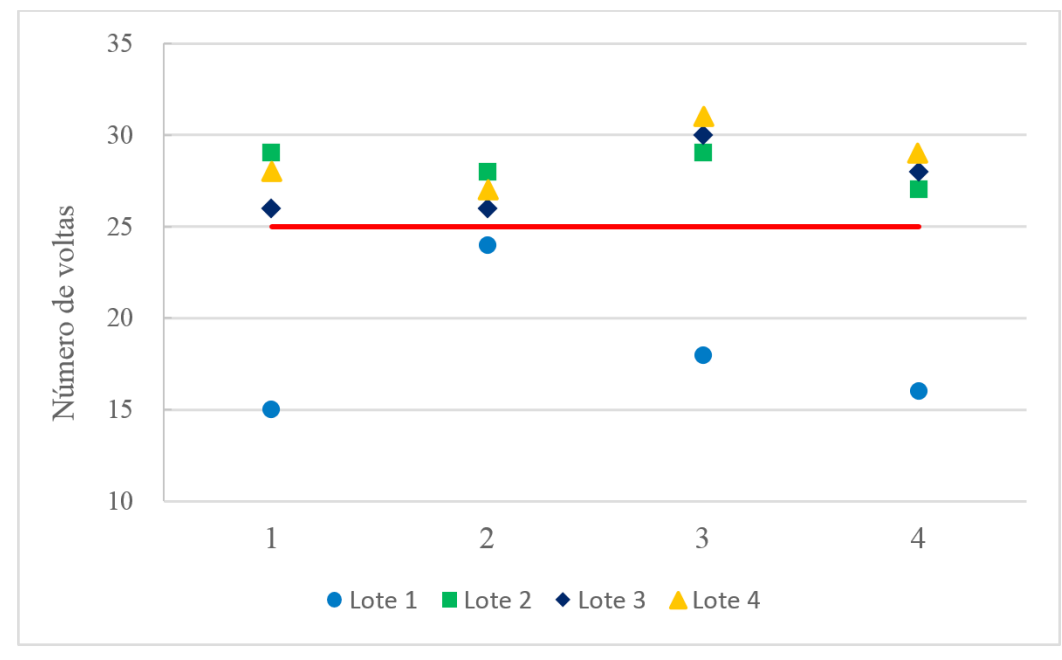

Fonte: Do autor, 2018

\section{CONCLUSÕES}

A adição de boro se tornou efetiva para reduzir os efeitos do envelhecimento, reduzindo o volume de nitrogênio livre na matriz com a precipitação do nitreto de boro no contorno do grão. Isso foi comprovado com a redução dos limites de resistência tanto no fio-máquina como nos arames.

No fio-máquina, foi possível confirmar o efeito do envelhecimento através da região de serrilhamento nas curvas de tensão e deformação. Foi possível, também, evidenciar a alteração no diagrama ferro-carbono provocada pela adição de boro, pois a amostra com maior teor de boro apresentou menor volume de fase ferrítica que a amostra sem boro. Através dos ensaios de tamanho de grão austenítico, ainda no fio-máquina, foi possível notar a capacidade do boro de atuar como inibidor do crescimento de grão. A amostra com 60 ppm de boro apresentou tamanho de grão $37 \%$ menor que a amostra sem boro. Por fim, por meio das análises fractográficas, não foi possível observar variações com a alteração do boro. Verificou-se apenas que ambas as fraturas analisadas são dúcteis.

Para os arames trefilados, as influências da adição de boro foram notadas, principalmente, na redução do limite de resistência. Houve uma redução de $11 \mathrm{kgf} / \mathrm{mm}^{2}$ com a adição de 60 ppm de boro. 0 efeito na ductilidade dos arames foi confirmado através do ensaio de torção de arames. As amostras com adição de boro obtiveram desempenhos similares e acima das de 25 voltas. Já a amostra sem boro, não atingiu o número mínimo de voltas, sendo reprovada no teste. A quebra da amostra sem boro indica o efeito do envelhecimento durante a aplicação desse produto e confirma a necessidade da adição de boro nesse material. 
Estudo da Influência do Boro no Aço 10B45 (Fio-máquina e Arame Trefilado),

analisando propriedades mecânicas e microestruturas

\section{REFERÊNCIAS}

ASSOCIAÇÃO BRASILEIRA DE NORMAS TÉCNICAS. ABNT NBR 7555: Aço - Revelação do grão austenítico. Rio de Janeiro, 1990. 5p

ASSOCIAÇÃO BRASILEIRA DE NORMAS TÉCNICAS. ABNT NBR 8965: Barras de aço CA 42 S com características de soldabilidade destinadas a armaduras para concreto armado. Rio de Janeiro, 1985. 4p

ASSOCIAÇÃO BRASILEIRA DE NORMAS TÉCNICAS. ABNT NBR ISO 6892-1: Materiais metálicos - Ensaio de tração Parte 1: Métodos de ensaio à temperatura ambiente. Rio de Janeiro, 2013. 80p

ASSOCIAÇÃO BRASILEIRA DE NORMAS TÉCNICAS. ABNT NBR 6003: Arames de aço - Ensaio de torção simples. Rio de Janeiro, 1984. 8p

COE, C.L., GORDON, A.T. Method for making strain aging resistant steel. EUA, 2006.

GONZALEZ, B.M.; BUONO, V. T. L.; VILELA, J. M. C E MANTEL, M. J. The influence of copper addition on the formability of AISI 304 stainless steel. Revista Materials Science and Engineering, v 343, p 51-56, 2003

KAPADIA, B.M. Effect of Boron Additions on the Toughness of Heat-Treated Low Alloy Steels, v 5, n 1, 1987.

KAPADIA, B.M. Hardenability Concepts with Applications to Steel, AIME, p 448, 1979.

MAITREPIERRE, PH.; ROFES-VERNIS, J.; THIEVELLIER, D. Structure- Properties relationships in boron Steels. AIME, p. 1, 1979.

MAKKI, K. High carbon steel wire superior in resistance to longitudinal cracking. EUA, 2001.

NAGAO, M. Very thin, high carbon steel wire and method of producing same. US7258756. KOBE STEEL. 21 ago. 2007NICHOLSON, M. E. Trans. AIME, p 185, 1954.

REIS, L. Estudo do efeito do boro e das condições de trefilação na delaminação de aços perlíticos. Belo Horizonte: Escola de Engenharia da UFMG, 83p. (Dissertação, Mestrado em Engenharia Metalúrgica), 2009.

TAHERI, A. K.; MACCAGNO, T. M. e JONAS, J. J; Dynamic Strain Aging and the Wire Drawing of LQWCarbon Steel Rods, Sharif University of Technology, Tehran, Iran. ISIJ International. Vol, 35, n. 12, p. 1532-1540, 1995

SHEN, X. P. e PRIESTNER, R. Effect of boron on the microstructure and tensile properties of dual-phase steel. Metallurgical Transactions A, v 21, p 2547 - 2553, 1990.

VOTORANTIM SIDERURGIA, Dados de produção, Resende 2017.

VOGT, J-B; ANTOINE, P.; e VANDEPUTTE, S. Empirical model predicting the value of the strain-hardening exponente of a Ti-IF steel grade. Universidade de Lille, França. Revista científica Materials Science \& Engineering, volume 433, p 55-63, 2006.

WANG, X. M.; HE, X. L., Effect of Boron Addition on Structure and Properties of ow Carbon Bainitic Steels, ISIJ International, Vol. 42, 2002. 